\title{
BIGHORN BASLN NATURAL RESOURCE DATA ASSESSMENT
}

\author{
Thomas A. Wesche \\ Stanley $\mathbf{w}$. Anderson \\ Walter H. Eifert \\ University of Wyoming \\ Laramie
}

\section{Objectives}

The primary goal of this study is to establish the mechanism for a benchmark evaluation of the natural resource conditions of the Bighorn Basin prior to 1983. To accomplish this goal, the principal objectives of this investigation are two fold:

1. By means of literature and computer searches and extensive personal communication with key personnel of a variety of agencies, institutions, and other entities, systematically locate and establish the sources, nature, and availability of both quantitative and qualitative data from the Bighorn Basin in wyoming dealing with:
a. aquatic and riparian habitat;
b. land and water uses;
c. wildlife and fishery resources; and
d. water resources.

2. Compile, categorize and key-word bibliographic information reviewed under Objective No. 1 , and enter these data onto a computerized bibliographic storage and retrieval system compatible with the University of wyoming's Cyber System.

Utilization of computer based information, storage and retrieval scftware will insure rapid bibliographic updating capability, provide the user with an expedient, low cost technigue for initial Basin-related literature reviews, and identify possible data gaps in those geographic areas within the Basin where deficiencies may occur.

\section{Methods}

The geographic area enconipassed by this investigation is that portion of the Bighorn Basin watershed in Wyoming drained by the Bighorn River and its major tributaries, e.g., the Wind, Greybull, Shoshone, and Nowood Rivers.

The approach taken to ensure cornplete documentation of all major Basin reports included extensive library and computer-based literature searches, contacts with key personnel representing fecieral, state and local agencies and universities, 
and the employment of a data survey questionaire.

Both published and unpublished citations secured from these sources were then topically and subtopically categorized to assure organizational clarity and to expedite the key-wording process.

Six major categories-wildlife, water resources, recreation, range, natural resources, and Basin-wide-reports-have been developed to manage the vast number of citations encountered to date. Additionally, up to 15 subcategories have been generated to further clarify the specific nature of the citation. Categorization by this technique will also be useful in data gap identification. Both the quantity and the quality of available reports under individual subcategorization headings will provide insight into any "weak links" in past Basin research. Retrieval by subcategory should, therefore, be useful to a resource manager in identifying future research needs within the Basin. Key-wording of each citation will then follow and will include both the major and subcategory previously assigned to each documented report. Before final modifications are made, however, this format will be tested for compatibility with the selected computer storage and retrieval system. Upon verification of format, representative samples of each major category and subcategory will be entered onto the system with subsequent test runs conducted to verify format, cross-referencing, and retrieval reliability. Remaining data files will then be loaded by major category with test runs conducted at 500 citation intervals for editing purposes.

\section{Results}

Bighorn Basin natural resource data available from Laramie area sources has been documented, with a "contact list" of key agencies and personnel involved witis research in the Basin, developed.

As a result of meetings held with personnel representing the U.S. Fish and Wildlife Service, Lander; the Wyorring Game and Fish Department, Lander and Cody; the National Park Service, Lovell; and the Bureau of Land Management, Worland, a data survey questionaire was developed and mailed to the list of contacts made to date. Additional meetings in Cheyenne with individuals representing ten state and five federal agencies significantly increased the number of key Basin sources remaining to be researchea.

Cheyenne area sources currently being investigated include the: State Engineers Office; Department of Environmental Quality; Wyoming Game and Fish Department; Wyoming Water Development Commission; Wyoming Travel Commission; Wyoming Recreation Commission; Wyoming Conservation Commission; Wyoming Highway Department; Wyoming Industrial Administration; Wyoming Public Lands; U.S. Soil Conservation Service; U.S. Bureau of Land Management; U.S. Bureau of Reclamation; U.S. Geological Survey; and the U.S. Forest Service.

Documentation of wyoming Game and Fish Department data files has recently been completed with that source alone contributing over 2,000 scientifically 
pertinent Basin citations. Current focus is on the Wyoming State Engineers Office, where an estimated 400 citations are available for inclusion in this study. Major Basin data depositories yet to be searched include these six: U.S. Bureau of Reclamation and U.S. Fish and Wildlife Service, Billings, Montana; National Park Service, Fort Smith, Montana; U.S. Fish and wildlife Service, Western Energy and Land Use Team and the U.S. Forest Service, Rocky Mountain Range and Experiment Station, Fort Collins, Colorado; and the Wyoming State Library, Archives Division, Cheyenne, wyoming.

A documentation review of four computer bibliographic storage and retrieval packages that would provide both flexibility and compatibility with study-generated data has been completed. Initial results indicate the FA NULUS package to be the most versatile, "user friendly" and inexpensive to operate and maintain. Additionally, FAMULUS software is currently available and is being updated on the University of Wyoming's Cyber System. Modifications are expected to be completed in the very near future, thereby providing immediate access to the system when the documentation portion of this study is completed.

\section{Conclusions}

Due to both the unexpected quantity and locations of Bighorn Basin data sources, citation collection, as outlined by objective \# 1 , is continuing. 'Io date, approximately 3,000 pertinent citations have been documented. As potential data depositories continue to be identified and investigated, it is not unforeseeable to project that the number of citations will exceed 6,000. To most efficiently utilize both manpower and travel allotments available for this study, initial contacts with each of the six remaining scurces has been conducted via telephone or data survey questionnaire. Prelininary responses have indicated significant quantities of Bighorn Basin material are located at these sources. Contingent with a continuation of this study, each of these sources will be thoroughily researched triereby insuring a very comprehensive end product. Presently, the primary focus of this study is in securing documentation from all available Cheyenne area sources. 